\title{
OIL FOR FOOD: THE GLOBAL STORY OF EDIBLE LIPIDS
}

\author{
Martin Pitts ${ }^{1}$ \\ Department of Classics \& Ancient History \\ University of Exeter \\ M.E.J.Pitts@exeter.ac.uk
}

Danny Dorling

Department of Geography

University of Sheffield

daniel.dorling@sheffield.ac.uk

Charles Pattie
Department of Geography
University of Sheffield
c.pattie@sheffield.ac.uk

\begin{abstract}
This paper addresses the issue of the globalization of food production and consumption in the last half-century through the medium of fats and oils, or lipids. The dual traits of being essential for human life and signifying a diverse range of regional styles of consumption make lipids an ideal bulk commodity to study international differences in food. FAOSTAT food balance sheet data on fats and oils from 1961 and 2003 are interrogated using correspondence analysis, which provides a means of displaying the principal trends in large tables of data. The analyses reveal evidence for a global convergence in lipid availability from 1961 to 2003 (from animal fats to vegetable oils), in addition to a trends towards an increased disparity which at the extremes is between the wealthiest, as importers of diversity, and least affluent regions, as the most resistant areas to homogenizing trends.
\end{abstract}

\section{INTRODUCTION}

In recent years it has been suggested that the world is undergoing a nutrition transition, characterised by a convergence on the so-called Western diet, high in saturated fats, sugar, and processed foods (Popkin 2003; Lieberman 2003). This trend has been associated with the response of food systems to the most recent phase of globalization, in which increased integration within the world economy has resulted in a supposed global homogenization of institutional, legal, economic, social and cultural practices (Kennedy, Nantel and Shetty 2004). Indeed, Lang (1999: 169) argued that "the food system is one key area in which a tension between globalization and internationalism is being fought out." Consequently, it is the aim of this paper to investigate globalization and the extent of any nutrition transition through an analysis of the changing patterns of global food consumption over the last halfcentury. The present study focuses on the consumption of one category of food - lipids, or oils and fats. Lipids represent an ideal commodity for the study of globalization processes, as they are a vital dietary component (through the provision of essential fatty acids) with a multitude of regional varieties. Also, unlike cereals, lipids can be interchanged without very obviously altering well known staples. They are also relatively light, per dollar, to transport - and so the trade and use of lipids reacts more rapidly and flexibly to changes in demand, and changes in the uneven distribution of resources.

\footnotetext{
${ }^{1}$ Corresponding author
} 


\section{JOURNAL OF WORLD-SYSTEMS RESEARCH}

\section{The Globalization of Food: Existing Approaches and Critique}

In the last decade or so the term globalization has become somewhat nebulous in both meaning and understanding. In an economic sense, globalization describes a process of integration into the world economy (Nayyar 2006). From this perspective, O'Rourke and Williamson (2002: 26) state that "the only irrefutable evidence that globalisation is taking place is a decline in the international dispersion of commodity prices or what might be called a commodity price convergence." Although some have suggested that there was a single world economy from at least c. 1500 (Wallerstein 1974), if not 5000 years ago (Frank and Gills 2000), O'Rourke and Williamson (2002) argued that the world was not truly globalized until the early nineteenth century, as a result of the then breakdown in long-distance trade monopolies and technological developments permitting the cheap transportation of bulk goods between continents. This view of a more recent qualitative shift is consistent with a recent observation of Chase-Dunn, Kawano and Brewer (2000), who identified three waves of trade globalization since 1795 .

However, defining globalization in purely economic terms is unsatisfactory, since the term gives no indication of the extent to which parallel convergences are taking place in other important spheres such as political institutions, cultural practice and social relations. Chase-Dunn (2005) delineates two meanings of globalization; 'structural globalization', which denotes "economic, political and cultural international and transnational integration" (ibid: 183), and the "globalization project', the political ideology of global corporate capitalism, which has drawn the attention of the anti-globalization movement. For the purposes of the present study, we equate the term globalization with the definition of structured globalization, unless otherwise indicated. This definition helps in the examination of why cultural and social integration has not kept up with the pace of economic integration, as Martinelli (2005: 241) contends: that although "we live in a world system as a growingly interconnected global order... a universal global society-as a network of social relations with mutual expectations plus a normative consensus reflected in commonly accepted institutionsdoes not exist yet."

It has been stated that "food embodies history like no other substance" (McMichael 2001: 216), and as such should represent a highly sensitive indicator of the consequences of globalization. Food has always been implicit in the many faceted process of globalization, from the late eighteenth century as part of the cargo of the mercantile sea trade that began with ship captains operating illegally in their self interest (Erikson and Bearman 2006) to much of the contents of standard sized cargo in the current peak of trade globalization (Chase-Dunn, Kawano and Brewer 2000). However, despite the current un-paralleled world trade peak, the world is not yet united in its tastes and stomachs, let alone in thinking, realising and operating as if we collectively belong to a "community of fate" (Martinelli 2005: 242). As such, the rest of this paper will address the effects of globalization on food consumption, and how this has changed within the period of human history characterised by a truly globalized economy.

Recent studies of food and globalization have tended to focus on the concept of convergence, which assumes a gradual homogenization of consumer choice in the modern global era (Traill 1997). For example, Gil, Gracia and Perez y Perez (1995) and Herrmann and Röder (1995) have demonstrated a general statistical convergence in food consumption patterns in the twentieth century, both globally and within the European Union respectively. Global trends such as the nutrition transition (Popkin 2003) and the livestock revolution (McMichael 2001) are explained in part by the moulding of taste by large multinational corporations, whereas large scale regional trends are strongly influenced by the policies of economic groupings dictating localized trends in agricultural production, such as the European Union and the North American Free Trade Agreement (Lang 1999). However, Traill (1997) argued that the evidence for food demand convergence is both mixed and subject to varying interpretation, citing cultural diversity and individualism as important factors leading to consumer resistance to global trends. Indeed, McMichael (2001) suggested that rather than representing the inevitable emulation of Western diets, the livestock revolution is more a product of 'Western developmentalism' fostered among emerging middle classes in developing countries by governments and multilateral agencies.

It is thus important to distinguish between general patterns of global food convergence, characterised by a worldwide shift towards a diet in which the principal sources of energy are derived 
from the same food groups (i.e. the nutrition transition) (Popkin 2003), and more regional and class specific trends of continuity (or even divergence) in cuisine. Indeed, Triall (1997: 407) stated that "strong local and national patterns of consumption remain firmly entrenched," which can be seen to be a product of a number of factors intrinsically related to globalization. Arguably most significant is the extent to which processes associated with globalization have caused increased divergence in income both between rich and poor countries, and between the rich and poor within countries (Nayyar 2006). Indeed, such inequalities (both within and between countries) have been cited as an integral part of the globalization process, both in the 19th century and the present day (Chase-Dunn 2005). As much as an increasingly globalized economy means that everyone (with sufficient resources) in the world has the opportunity to consume the same foods as everyone else, dietary homogenization is far from inevitable, and where it does occur is likely to reflect growing poverty through inequality. Not everyone is financially empowered to participate in the global market (many must fall back on traditional or cheap sources of nutrition), whereas those who are affluent enough to participate are often reacting against global mass-produced and processed foods to construct cuisines favouring fresh and diverse local produce (Lang 1999).

\section{The Significance of Lipids: Food and Function}

Lipid intake is essential for human life. A healthy adult needs approximately 5 grams a day of linolenic acid, an unsaturated fatty acid that cannot be manufactured within the body (McNutt and McNutt 1978). As a source of energy, lipids provide over twice as much per gram as carbohydrates or protein (Grigg 1999a), and are the most efficient means of meeting undernourishment where sheer calorific intake is the primary dietary requirement (Gunstone 1989). Since the early 1980s World Health Organisation dietary recommendations advise that around 30\% of human calorific intake should come from fats, including 10\% from saturated fats (Marr 1985). In addition, lipids provide a valuable source of fat soluble vitamins A, D, E and K (Vergroesen and Gottenbos 1975). Fats and oils can also have multiple uses beyond that as a food staple. For example, olive oil was being used as lighting fuel and the base ingredient for a range of medicines, soaps and cosmetics as early as the Roman period in Europe and the Mediterranean (Mattingly 1988).

Recent media attention has focused on the potential health side-effects of a high-lipid intake, in addition to the health benefits of consuming particular varieties over others. Excessive dietary intake of fats has been directly related to an increased risk of obesity, coronary heart disease and some cancers, with lipids high in saturated fats causing an elevation in blood cholesterol (FAO 1994). Accordingly, the British media now advises people in the UK (where the authors of this paper live) to consume less saturated fat (prevalent in animal fats such as butter and whole milk) and more unsaturated fats (prevalent in vegetable oils such as sunflower oil and olive oil). No doubt such stories of the damages that can be caused when an abundance of fats are available are increasingly a feature of the health related news in many other affluent nations. Often in those nations it is the working class who are most admonished for their consumption of cheaper and more heavily advertised products.

Perhaps in part relating to the changing role of fats and oils in health and nutrition, lipid consumption can also be seen as a means of marking social class, ethnicity and even religious identity in modern society. Bourdieu (1984) argued that an essential criterion defining differences between the working and the middle classes is the preference of the former for "taste of necessity, which favours the most 'filling' and the most economical foods" and the preference of the latter for the "taste of liberty - or luxury - which shifts the emphasis to the manner (of presenting, serving, eating etc.) and tends to use stylized forms to deny function." Trichopoulou, Naska and Costacou (2002) report that individuals from lower socio-economic groups in Europe are known to consume more lipids and saturated fats than those from more affluent groups, and it is perhaps no coincidence that in recent years the working classes in industrialized countries have borne the brunt of obesity and other saturated fat related illnesses (e.g. Brunner et al. 1997). Indeed, analysis of the 1958 birth cohort in the UK revealed statistical linkages between lower social class and obesity (Power and Moynihan 1988). At the other end of the social hierarchy, a recent newspaper article extolling the health virtues of a range of obscurer vegetable oils reports that certain varieties have become so highly prized by wealthy connoisseurs that they sell for up to $£ 40$ per litre (Watson 2006). Ethnic minorities associated 
with recent immigration streams are likely to include many people with a prejudice for oils from their area of origin, sometimes governed by religious prohibitions (for example, the Old Testament forbids the consumption of ox, sheep or goat fat: Leviticus 7:23-5; cited Gidez 1984: 1432).

In addition to marking vertical stratification in society, lipids have been noted for their ability to indicate specific horizontal or regional differences in global food consumption and cuisine (Grigg 1999a). The dual characteristics of being essential for human life with the capacity to signify a diverse range of regional styles of consumption make lipids an ideal bulk food commodity class to use to study globalization. The localized nature of lipid production and consumption is particularly significant in regard to elucidating global trends, distinguishing oils and fats from other important staples such as cereals and livestock, whereas other regionally specific food categories (e.g. spices) lack the tag of being essential dietary components. The regional patterning in lipid production and consumption is due to a combination of factors, including the specific climatic requirements of certain oil crops such as the olive (Grigg 2001); the capacity of wealthier countries to invest in technology to process oil crops hitherto unsuitable for human consumption (such as rape: Tanaka, Juska and Busch 1999); and a general world-wide bio-diversity of oil sources that remain viable for mass-exploitation in the modern era. Nevertheless, despite the obvious potential of fats and oils for illuminating global patterns of food intake, the geography of lipid consumption has received relatively little attention in recent years beyond the work of David Grigg (1993, 1999a, 1999b, 2001). However, before this is approached, the longer term history of lipid use in food preparation needs to be understood.

\section{A Brief History of Lipids in Food}

On an evolutionary scale, the consumption of lipids from dairy sources and refined vegetable oils is a relatively recent phenomenon, dating back c. 10-11,000 years for the domestication of sheep, goats and cattle, and c. 6000 years for the cultivation of olive oil (Cordain et al. 2005). Several other edible oil crops have enjoyed a similar history of cultivation to olive oil. For example, archaeological and documentary evidence suggests that sesame oil competed with the olive in the Mediterranean basin and India from at least 1137 BC (Horden and Purcell 2000); the Aztecs produced groundnut oil in South America long before the arrival of European settlers in the fifteenth century; and palm oil originated in West Africa and was spread to the Americas and Indonesia in the sixteenth century (Toussaint-Samat 1992). But only in the last century did the biggest changes occur in global lipid consumption. These changes can be attributed to the Industrial Revolution, in which a combination of technological development, and the beginnings of large-scale food production and a truly global market took place (Cordain et al. 2005; O'Rourke and Williamson 2002). For example, until the late nineteenth century, the only edible oil-bearing crop grown in Europe was the olive, with the rest of the continent relying on animal fats as the principal source of cooking oil (Grigg 1993). The principal technological developments include the advent of mechanically driven steel expellers and hexane extraction processes (increasing vegetable oil productivity), new purification processes (permitting the exploitation of hitherto non-food oils such as cottonseed), and new manufacturing procedures such as hydrogenation, allowing vegetable oils to take on atypical structural characteristics used in the production of margarine from 1897 (Cordain et al. 2005).

There have been several important changes to lipid production in the twentieth century. By the late 1980s the dominant vegetable oils in world markets were soya, palm, sunflower and rape (Gunstone 1989), yet none of these accounted for any significant proportion of global production in 1900 (Grigg 1999a). Most food may be consumed where it is produced, but that is no longer the case for lipids. Palm oil became an important global source from the 1920s when it began to be grown on plantations in south-east Asia, whereas rape, soya, and sunflower oil underwent rapid production increases from the 1950s in the United States (soya), USSR (sunflower) and Canada, China and northern Europe (rape) (Grigg 1999a). With the exception of palm oil (a tree crop), the most successful oils have either been by-products like soya, with their production controlled by demand for a product other than oil, or annual crops like sunflower and rape, which are able to respond more quickly to changing market demand (Gunstone 1989).

Although the transition away from animal products and towards vegetable oils containing polyunsaturated fatty acids could be an indicator of increased awareness of the beneficial health properties of these commodities, Grigg (1999a) argued that this is more likely a consequence of the 
relative cheapness of vegetable oils relative to animal fats. Indeed, relative cost appears destined to be a major barrier to the widespread future consumption of the latest oils identified to have healthy properties, especially olive oil and oily fish (a source of omega 3), with only $1 \%$ of the earth's land surface suitable for production of the former (Grigg 2001), and the latter being dependent on rapidly dwindling world fish stocks (Brunner 2006). Therefore, the extent to which the majority of the southern hemisphere is "condemned to repeat the modernising northern hemisphere diet" (McMichael 2001: 217) is far from certain.

\section{DATA AND METHODS: TOWARDS A GEOGRAPHY OF LIPIDS}

Grigg's (1999a) study of international variations in the consumption of fats and oils in the early 1990s forms an important starting point for the present study, citing economic development, regional traditions and climate as major factors contributing to patterns of global diversity. However, Grigg was not explicitly concerned with using lipids to address the phenomenon of globalization, and consequently there remain a number of unresolved questions and issues. Paramount among these is the extent to which there have been changes in lipid consumption over a prolonged period of time, and whether or not it is possible to identify patterns of global convergence and/or regional conservatism and/or divergence. In Herrmann and Röder's (1995) quantitative analysis of global food consumption it was noted that vegetable oils did not exhibit statistically significant convergence, yet it is unclear whether this pattern holds true for fats and oils when considered as individual varieties. Therefore, to achieve more meaningful results it is important to compare the consumption of all varieties of fats and oils for each country or region, instead of concentrating on only the primary source of lipids (as per Grigg 1999).

In this study, emphasis is placed on the market availability and importation (as opposed to production and exportation) of lipids as a means of consciously addressing the issues of dietary preference and food choice. The raw data used in analysis have been acquired from the United Nations Food Balance Sheets (FAOSTAT 2006), which provides food-related data for nearly all of the UN member states from 1961 to 2003. Figures for food availability are obtained by taking those for production, adding imports and foods in store, and then subtracting exports and figures for food used in industry and animal feed (Grigg 1999a). In terms of utilization, a distinction is made between the quantities exported, fed to livestock, used for seed, processed for food use and non-food uses, lost during storage and transportation, and food supplies available for human consumption at the retail level, as the food leaves the retail shop or otherwise enters the household (FAO 2001). Per capita values in kilograms per year were then calculated by dividing the consumption figure in metric tons by a country's population in 1000s (FAOSTAT 2006).

Consequently, the Food Balance Sheets provide data primarily relating to food supplies available for human consumption at a retail level (FAO 2001), and thus can be used as estimates of direct consumption patterns. Although waste is accounted for based on figures obtained from the oil industry for individual oil crops (FAO 2001), these figures are only estimates. Not all food that is consumed is traded, with an additional problem being the omission of data from non-commercialised food production and consumption (FAO 2001), adding a further element of error into any subsequent analysis. Indeed, McMichael (2001: 215) stated that "only about 20\% of the world's six billion population participate in the cash or consumer credit economy, and about $90 \%$ of the world's food consumption occurs where it is produced. While urbanites depend on the market for almost all their food consumption, rural populations consume $60 \%$ of the food they produce." It is envisaged that in the context of this paper the main effect of such distortion would be to under represent the diversity of fats and oils consumed in a particular country (although it is arguable that any significant noncommercial patterns of consumption would show up in the mass market anyway). Nevertheless, in spite of these factors, and in the absence of detailed international household surveys for the last 50 or so years, the Food Balance Sheets are thought to present a reliable overview of the principal differences in consumption patterns on a global scale (Grigg 1999). In short - can we detect changing in what we are becoming - from what we are now differently eating?

Per capita data on world lipid consumption and importation in 1961 and 2003 is presented in tables 1-4. These data were then interrogated using the multivariate technique of correspondence 
analysis (hereafter referred to as CA), which presents a means of displaying trends in complex datasets in two dimensions for visual display (using Minitab). CA is related to the more widely used multivariate method of principal components analysis (PCA), with the main difference being that CA is more suited to the analysis of categorical variables (Greenacre and Hastie 1987). Although not widely used in some social sciences such as geography, CA has become popular in other disciplines where large cross-tabulations of data are unwieldy for more basic statistical analysis, such as sociology (e.g. Bourdieu 1984), market research (Hoffman and Franke 1986) and archaeology (e.g. Shennan 1997; Cool and Baxter 2002; Pitts 2005). An added advantage of using CA over PCA is that it produces a pair of dual displays whose row and column geometries have similar interpretations (Hoffman and Franke 1986), with patterns in the first set of categorical variables or rows (types of lipid, for example) directly corresponding to the respective patterns in the second set of categorical variables (regional groupings of countries, for example).

The axes of the CA plots essentially measure the amount of variation from the average, with the most typical countries and the most widely consumed lipids occurring closest to the point where the graph axes cross, and the most unusual occurring at the plot extremes (see Greenacre 1993 for the mathematical underpinning of this technique). By default the components or axes selected by the computer software in CA are usually the first and second, which together account for the most inertia (the amount of departure from the average, or the amount of variability). However, it is sometimes necessary to look at other components (e.g. the first and third) if over-clustering of the first and second components renders visual interpretation problematic. All the CA plots here are symmetrically scaled. This means that the relationships between directly corresponding regions and lipids can only be assessed relatively, not absolutely. It is important to stress that CA is not intended as a form of absolute statistical testing. To account for this, any patterning of note was verified by reference to the original data-sets.

Interpretation of the CA plots shown here is as follows. Each run of CA produces two plots (relating to the rows and columns of the original tables of data), which can either be presented separately or superimposed on top of one another. In this example, one plot displays the different regional groupings according to their similarities and differences in lipid consumption (fig. 1b), whereas the other presents the individual varieties of fats and oils according to their availability or importation in different regions (fig. 1a). Regions with similar lipid availability or importation profiles will cluster in the first plot, while lipids consumed in similar localities will cluster in the second. The area of the first plot directly corresponds to the same area on the second, hence the term 'correspondence analysis.' Ideally, the plots should be presented overlapping one another on the same space (e.g. fig. 2) to aid interpretation (i.e. to spot which lipids characterise particular regional groupings and vice versa). However, in circumstances where there are large numbers of categories or excessive clustering it is sometimes preferable to display the row and column plots separately (e.g. figs $1 \mathrm{a}$ and $1 \mathrm{~b}$ ). In order to aid interpretation in this case-study, the main trends have been manually highlighted on the CA plots, with \% inertia values labelled for all components.

For the purposes of analysis in this paper, food balance sheet data for 1961 and 2003 were directly compared (FAOSTAT 2006), representing the broadest possible timeline available from the FAOSTAT database. Supplementary data for the UK in intervening years were also selected, for the primary purpose of illustrating the rate of change in food availability and imports. Ideally it should be possible to plot consumption timelines for each UN member state, although this was not possible without severe overcrowding of CA plots, rendering visual interpretation impossible. The best compromise was to split the geographical data into eighteen regions, reflecting factors of locational proximity, economic well-being and living standards, agricultural and climactic regimes, and food cultures (selected regions exhibiting a strong degree of consistency with other notable attempts to map geographies of food habits, e.g. Dyson 1996, Grigg 1999b, and Millstone and Lang 2003). The main patterns are discussed in turn below. 


\section{Lipid Availability Per Capita, 1961 - 2003}

Correspondence analysis of lipid availability patterns are presented in figures $1 \mathrm{a}-\mathrm{b}$ and 2 , with the corresponding per capita data in tables 1-2. Figures 1a-b display the CA results for individual fats and oils for 1961 and 2003, with the plot for lipids presented in figure 1a and that for the regions in figure $1 \mathrm{~b}$. In contrast, figure 2 presents the CA results for grouped fats and oils (e.g. animal fats), with lipids and regions overlapping on the same plot. Figures 1 and 2 both contrast lipid availability from 1961 and 2003, with supplementary points added at 3-year intervals for the UK as an additional case-study, which gives some indication of the rate and trajectory of change over time. In both figures 1 and 2, components other than the first and second were selected for CA (the second and third for fig. 1; the first and third for fig.2). This measure was taken to overcome the excessive clustering of data points when the first two components were initially plotted, thus facilitating visual interpretation. The main trends in the results are interpreted below.

In figure 1, the principal trends are indicated by the vertical axis (component 2), which can be seen to roughly represent change over time, with lipids favoured in 1961 largely occurring in the upper two quadrants and those favoured in 2003 being plotted in the lower two quadrants. Not only does this pattern indicate an almost linear shift in world lipid consumption over time (from the top two quadrants to the bottom two), it also indicates a transition from a picture of relatively diverse consumption in the early 1960s to one of increased homogeneity in 2003 (figure 1a), with eleven lipid varieties broadly corresponding to the majority of 1961 regions in the upper half of the plots, and only five oils corresponding to the bulk of 2003 regions in the lower two quadrants. The main characteristics of this transition include a reduced emphasis on animal fats and fish oils (in more wealthy regions, especially Australia and New Zealand, Northern Europe and the UK and Ireland) and certain vegetable oils (in less affluent regions, particularly sesame, palmkernel and groundnut oils in Central and South America), accompanied by a corresponding convergence on small number of vegetable oils, especially soyabean, rape and maize (figure 1a). This trend is clearly demonstrated by the supplementary points for the UK at three-year intervals, illustrating a gradual transition from animal and fish derived lipids to vegetable oils, in particular oilseed rape. Here the period of most rapid change appears to be from the mid-1970s to the late 1980s. Other notable patterning in this vein includes a general convergence of North, South and Central America on consuming soyabean oil, and the shift of temperate wealthy regions such as Australia and New Zealand and northern Europe from animal fats towards vegetable oils.

Nevertheless, there are several significant trends in figure 1 that do not fit the general pattern described above. A number of regions (all in the upper-right quadrant) fail to show any signs of convergence, particularly southern Europe (closely corresponding to olive oil as an outlier in 1961 and 2003), western Africa (a region partly blighted by war, poverty and famine throughout the period in question), and the former USSR (which shows a relative shift towards divergence with the consumption of sunflower oil in 2003). Conversely, the 1961 points for Japan \& South Korea, East Asia and North America all feature in the 2003 dominated area of figure 1b (lower-left quadrant), highlighting these regions as traditional consumers (or even trend setters) in respect to the globalizing trend towards soya oil (all three regions) and rape oil (Japan and South Korea) (corresponding area of figure 1a). 


\section{JOURNAL OF WORLD-SySTEMS RESEARCH}

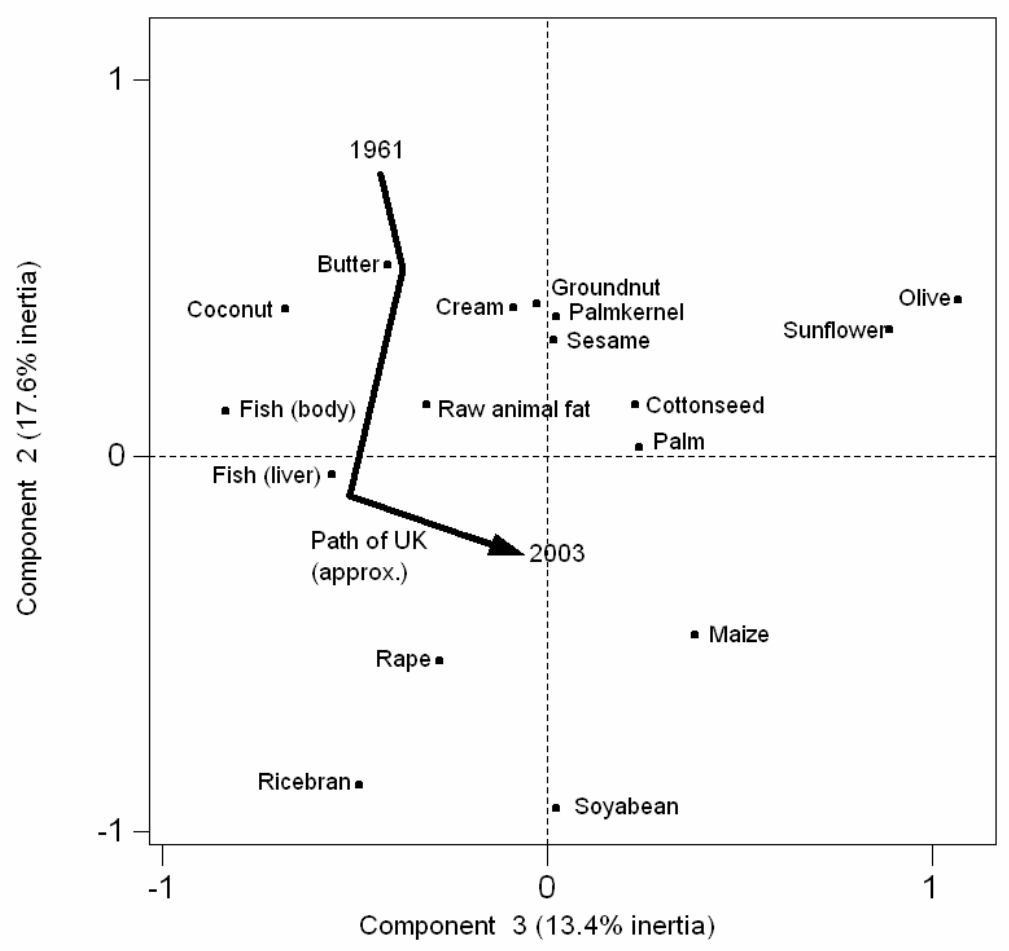

Figure 1a: Correspondence analysis - edible lipids plotted by their availability in different world regions in 1961 and 2003.

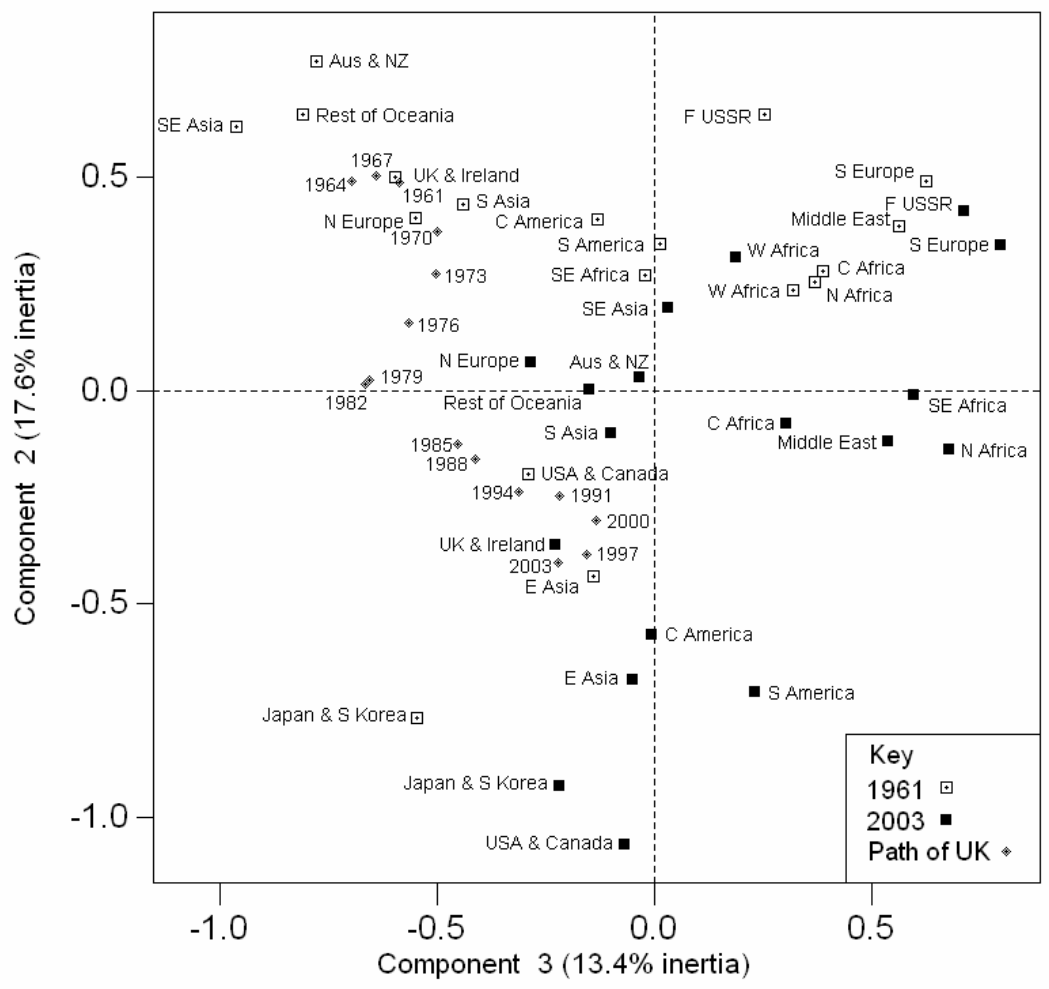

Figure 1b: Correspondence analysis - world regions plotted by the availability of different edible lipids in 1961 and 2003. 
Table 1: World lipid availability, Kg/capita/year, 1961 (Source: FAOSTAT data, 2006).

\begin{tabular}{|c|c|c|c|c|c|c|c|c|c|c|c|c|c|c|c|c|c|}
\hline 总 & $\stackrel{\Xi}{\Xi}$ & 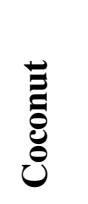 & 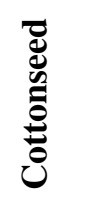 & ఏ్ & 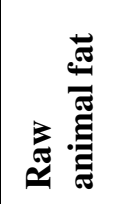 & 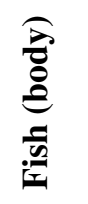 & 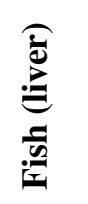 & 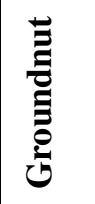 & 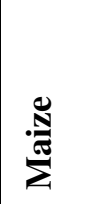 & $\stackrel{\bar{\partial}}{\overline{0}}$ & Е & 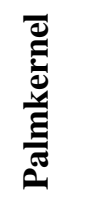 & $\underset{\mathscr{\Xi}}{\stackrel{\Xi}{\sharp}}$ & 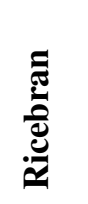 & 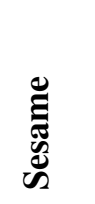 & 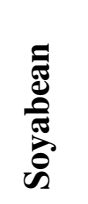 & 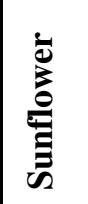 \\
\hline Aus \& NZ & 12.38 & 1.42 & 0.04 & 0.56 & 3.94 & 0.00 & 0.02 & 0.64 & 0.02 & 0.39 & 0.09 & 0.00 & 0.02 & 0.00 & 0.00 & 0.20 & 0.07 \\
\hline C Africa & 0.06 & 0.00 & 0.15 & 0.00 & 0.18 & 0.00 & 0.00 & 0.80 & 0.00 & 0.10 & 2.76 & 0.30 & 0.00 & 0.00 & 0.01 & 0.00 & 0.07 \\
\hline C America & 0.40 & 0.88 & 1.52 & 0.00 & 1.69 & 0.00 & 0.00 & 0.20 & 0.03 & 0.11 & 0.39 & 0.00 & 0.02 & 0.00 & 1.01 & 0.15 & 0.35 \\
\hline E Asia & 0.03 & 0.02 & 0.12 & 0.00 & 0.24 & 0.00 & 0.00 & 0.22 & 0.01 & 0.00 & 0.06 & 0.00 & 0.18 & 0.02 & 0.10 & 0.43 & 0.02 \\
\hline F USSR & 3.88 & 0.00 & 0.64 & 1.44 & 2.29 & 0.00 & 0.00 & 0.01 & 0.04 & 0.02 & 0.00 & 0.00 & 0.13 & 0.00 & 0.02 & 0.06 & 4.19 \\
\hline Japan \& S Korea & 0.11 & 0.17 & 0.20 & 0.00 & 0.60 & 0.23 & 0.06 & 0.03 & 0.00 & 0.00 & 0.00 & 0.04 & 0.80 & 0.32 & 0.00 & 1.05 & 0.00 \\
\hline Middle East & 1.87 & 0.08 & 1.67 & 0.10 & 0.29 & 0.00 & 0.00 & 0.01 & 0.12 & 1.73 & 0.00 & 0.00 & 0.00 & 0.00 & 0.24 & 0.79 & 0.56 \\
\hline N Africa & 1.10 & 0.07 & 2.27 & 0.00 & 0.66 & 0.00 & 0.00 & 0.26 & 0.00 & 1.08 & 0.02 & 0.00 & 0.53 & 0.00 & 0.00 & 0.50 & 0.33 \\
\hline N Europe & 7.17 & 1.55 & 0.57 & 2.98 & 7.48 & 0.83 & 0.05 & 0.58 & 0.07 & 0.07 & 0.51 & 0.61 & 1.23 & 0.00 & 0.02 & 1.43 & 0.98 \\
\hline Rest of Oceania & 0.48 & 0.51 & 0.00 & 0.00 & 0.40 & 0.00 & 0.00 & 0.45 & 0.00 & 0.00 & 0.02 & 0.00 & 0.07 & 0.00 & 0.00 & 0.00 & 0.00 \\
\hline S America & 0.66 & 0.47 & 1.34 & 0.00 & 2.18 & 0.00 & 0.00 & 0.54 & 0.16 & 0.09 & 0.16 & 0.35 & 0.10 & 0.00 & 0.19 & 0.33 & 0.94 \\
\hline S Asia & 1.00 & 0.38 & 0.26 & 0.00 & 0.09 & 0.00 & 0.00 & 1.84 & 0.00 & 0.00 & 0.00 & 0.00 & 0.78 & 0.02 & 0.22 & 0.04 & 0.00 \\
\hline SE Asia & 0.02 & 1.61 & 0.03 & 0.00 & 0.40 & 0.00 & 0.00 & 0.48 & 0.01 & 0.00 & 0.09 & 0.02 & 0.00 & 0.01 & 0.12 & 0.03 & 0.00 \\
\hline SE Africa & 0.62 & 0.29 & 0.34 & 0.00 & 0.51 & 0.00 & 0.00 & 0.42 & 0.65 & 0.02 & 0.03 & 0.01 & 0.06 & 0.00 & 0.01 & 0.03 & 0.28 \\
\hline S Europe & 2.51 & 0.24 & 0.22 & 0.31 & 2.56 & 0.03 & 0.03 & 1.42 & 0.20 & 4.77 & 0.15 & 0.22 & 0.17 & 0.00 & 0.06 & 1.00 & 1.19 \\
\hline UK \& Ireland & 9.42 & 0.84 & 0.52 & 0.76 & 8.26 & 0.93 & 0.00 & 1.13 & 0.13 & 0.05 & 2.58 & 0.83 & 0.05 & 0.00 & 0.00 & 0.78 & 0.06 \\
\hline USA and Canada & 3.68 & 0.70 & 2.92 & 1.12 & 7.19 & 0.00 & 0.00 & 0.19 & 0.72 & 0.15 & 0.16 & 0.11 & 0.04 & 0.00 & 0.00 & 6.54 & 0.00 \\
\hline W Africa & 0.16 & 0.14 & 0.10 & 0.00 & 0.20 & 0.00 & 0.00 & 1.66 & 0.00 & 0.01 & 6.14 & 0.09 & 0.00 & 0.00 & 0.16 & 0.02 & 0.00 \\
\hline
\end{tabular}




\section{JOURNAL OF WORLD-SYSTEMS RESEARCH}

With many of the animal fats and vegetable oils lumped into composite categories, figure 2 confirms the principal trends apparent in figure 1. On this plot, our main interpretation rests on the horizontal axis (component 1), which appears to broadly indicate economic well-being, with wealthier regions (e.g. Europe and North America) generally plotted on the left half of the graph and those less affluent (e.g. parts of sub-Saharan Africa and south-east Asia) on the right. In addition, the passage of time is indicated by a convergence on the plot centre from 1961 to 2003, indicating a transition from relatively diverse global lipid availability in 1961 to one based more on soya and rape oil in 2003. Consequently, figure 2 draws more clear-cut distinctions between inter-regional groupings, particularly the temperate richer regions and their transition from animal fats to rape and soya oil consumption, and less-affluent countries largely corresponding to the composite vegetable oils category. As with figure 1, certain regions are characterised by a degree of resistance to global convergence, especially southern Europe (olive oil), the former USSR (sunflower oil) and the poorest regions (particularly West Africa, Central Africa and south-east Asia). The broader implications of the patterns highlighted from figures 1 and 2 are discussed below following an initial overview of the analysis of lipid imports per capita.

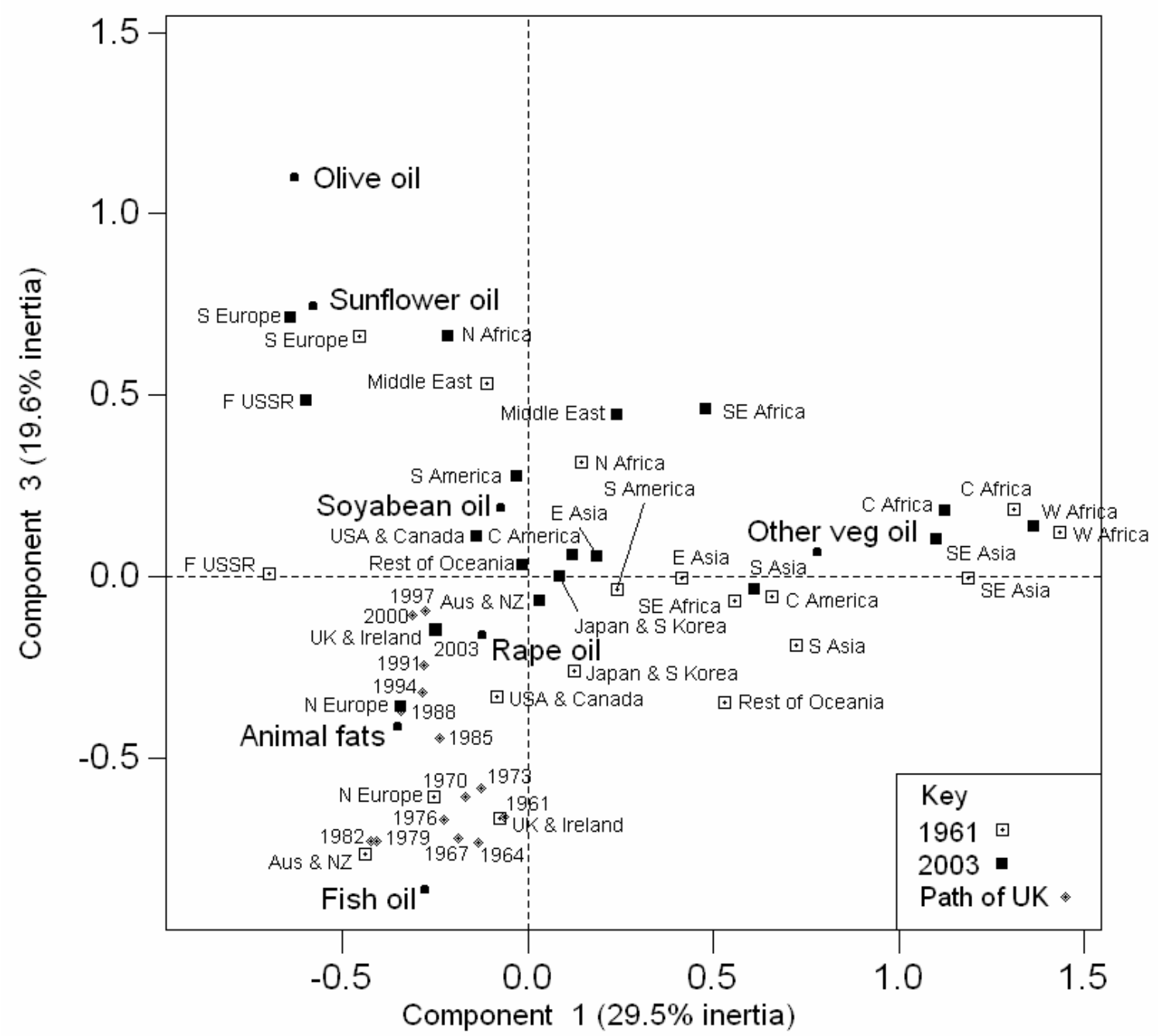

Figure 2: Correspondence analysis - the availability of simplified edible lipid categories by world region in 1961 and 2003. 
Table 2: World lipid availability, Kg/capita/year, 2003 (Source: FAOSTAT data, 2006).

\begin{tabular}{|c|c|c|c|c|c|c|c|c|c|c|c|c|c|c|c|c|c|}
\hline œ & 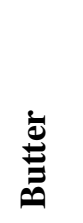 & 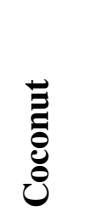 & 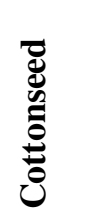 & 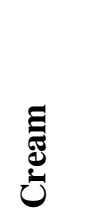 & 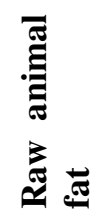 & 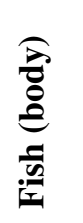 & 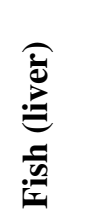 & 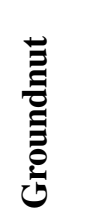 & 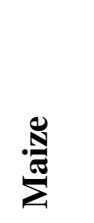 & 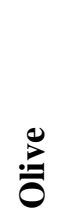 & $\stackrel{\Xi}{\text { ฮ }}$ & 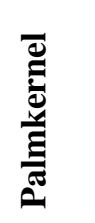 & 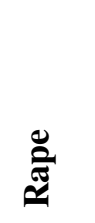 & 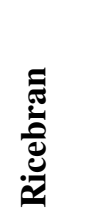 & 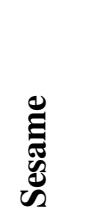 & 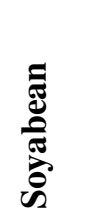 & 㐫 \\
\hline Aus \& NZ & 4.45 & 0.65 & 2.04 & 0.03 & 3.58 & 0.00 & 0.02 & 0.12 & 0.20 & 1.36 & 4.07 & 0.00 & 5.11 & 0.00 & 0.15 & 1.39 & 1.64 \\
\hline C Africa & 0.04 & 0.00 & 0.07 & 0.00 & 0.19 & 0.00 & 0.00 & 0.58 & 0.01 & 0.01 & 2.89 & 0.46 & 0.10 & 0.00 & 0.08 & 0.79 & 0.10 \\
\hline C America & 0.52 & 0.50 & 0.29 & 0.12 & 2.38 & 0.00 & 0.00 & 0.04 & 0.34 & 0.09 & 1.95 & 0.00 & 0.60 & 0.00 & 0.02 & 4.48 & 0.64 \\
\hline E Asia & 0.11 & 0.12 & 0.55 & 0.00 & 2.19 & 0.00 & 0.01 & 1.19 & 0.07 & 0.01 & 1.53 & 0.02 & 1.77 & 0.06 & 0.14 & 5.07 & 0.46 \\
\hline F USSR & 2.29 & 0.02 & 1.22 & 1.50 & 1.89 & 0.00 & 0.00 & 0.00 & 0.24 & 0.03 & 0.00 & 0.00 & 0.15 & 0.00 & 0.00 & 1.09 & 6.92 \\
\hline Japan \& S Korea & 0.88 & 0.54 & 0.21 & 0.01 & 0.92 & 0.33 & 0.00 & 0.01 & 0.63 & 0.21 & 1.22 & 0.11 & 4.43 & 0.33 & 0.16 & 6.29 & 0.14 \\
\hline Middle East & 1.59 & 0.08 & 1.18 & 0.15 & 0.45 & 0.00 & 0.00 & 0.01 & 0.87 & 0.92 & 2.70 & 0.34 & 0.14 & 0.00 & 0.24 & 3.03 & 2.13 \\
\hline N Africa & 1.62 & 0.10 & 0.31 & 0.00 & 0.34 & 0.00 & 0.00 & 0.35 & 0.92 & 1.05 & 0.46 & 0.11 & 0.35 & 0.00 & 0.00 & 3.00 & 3.09 \\
\hline N Europe & 4.76 & 1.32 & 0.00 & 5.43 & 7.14 & 0.20 & 0.00 & 0.38 & 0.30 & 0.42 & 0.81 & 0.14 & 4.39 & 0.00 & 0.06 & 3.90 & 2.34 \\
\hline Rest of Oceania & 0.76 & 0.43 & 0.00 & 0.29 & 0.38 & 0.00 & 0.00 & 0.11 & 0.04 & 0.08 & 0.12 & 0.05 & 0.02 & 0.00 & 0.00 & 0.98 & 0.40 \\
\hline S America & 0.52 & 0.04 & 0.59 & 0.03 & 2.23 & 0.19 & 0.00 & 0.07 & 0.43 & 0.09 & 1.87 & 0.11 & 0.05 & 0.04 & 0.01 & 7.24 & 1.90 \\
\hline S Asia & 2.26 & 0.37 & 0.56 & 0.00 & 0.22 & 0.00 & 0.00 & 1.06 & 0.02 & 0.00 & 3.62 & 0.01 & 1.07 & 0.67 & 0.11 & 1.59 & 0.38 \\
\hline SE Asia & 0.11 & 1.18 & 0.04 & 0.08 & 0.80 & 0.00 & 0.00 & 0.45 & 0.06 & 0.01 & 4.01 & 0.94 & 0.01 & 0.03 & 0.21 & 0.54 & 0.25 \\
\hline SE Africa & 0.17 & 0.25 & 0.35 & 0.02 & 0.45 & 0.00 & 0.00 & 0.25 & 0.51 & 0.04 & 1.51 & 0.09 & 0.06 & 0.00 & 0.04 & 0.79 & 1.45 \\
\hline S Europe & 3.19 & 0.29 & 0.12 & 2.60 & 4.14 & 0.13 & 0.01 & 0.43 & 0.65 & 6.61 & 0.44 & 0.05 & 1.18 & 0.00 & 0.04 & 2.78 & 7.53 \\
\hline UK \& Ireland & 3.36 & 0.47 & 0.01 & 0.32 & 3.44 & 0.19 & 0.02 & 0.12 & 0.36 & 0.78 & 1.22 & 0.01 & 6.38 & 0.00 & 0.04 & 4.05 & 1.30 \\
\hline USA and Canada & 2.14 & 0.27 & 0.68 & 0.77 & 4.39 & 0.00 & 0.00 & 0.36 & 1.42 & 0.71 & 0.00 & 0.05 & 2.21 & 0.00 & 0.00 & 20.23 & 0.14 \\
\hline W Africa & 0.14 & 0.14 & 0.53 & 0.00 & 0.28 & 0.00 & 0.00 & 3.30 & 0.01 & 0.01 & 4.29 & 1.15 & 0.05 & 0.00 & 0.18 & 0.47 & 0.03 \\
\hline
\end{tabular}




\section{JOURNAL OF WORLD-SYSTEMS RESEARCH}

\section{Lipid Imports Per Capita, 1961 - 2003}

Consideration of imports in their own right provides a potentially vital insight into the extent to which global changes in lipid availability (see above) are being driven by international trade or merely reflect local changes in agricultural production. In a similar manner to the availability data, correspondence analysis of lipid imports is presented in figures $3 a-b$ and 4 , with the corresponding per capita data in tables 3-4. Figures 3a-b display the CA results for individual fats and oils for 1961 and 2003 , with the lipids plotted in figure $3 \mathrm{a}$ and the regions in figure $3 \mathrm{~b}$. In contrast, figure 4 presents the CA results for grouped fats and oils (e.g. animal fats), with lipids and regions overlapping on the same plot. Figures 1 and 2 both contrast imports from 1961 and 2003, with supplementary points added for the UK at 3-year intervals, again as an additional case-study, which gives some indication of the rate and trajectory of change over time. The main trends in the results are interpreted below.

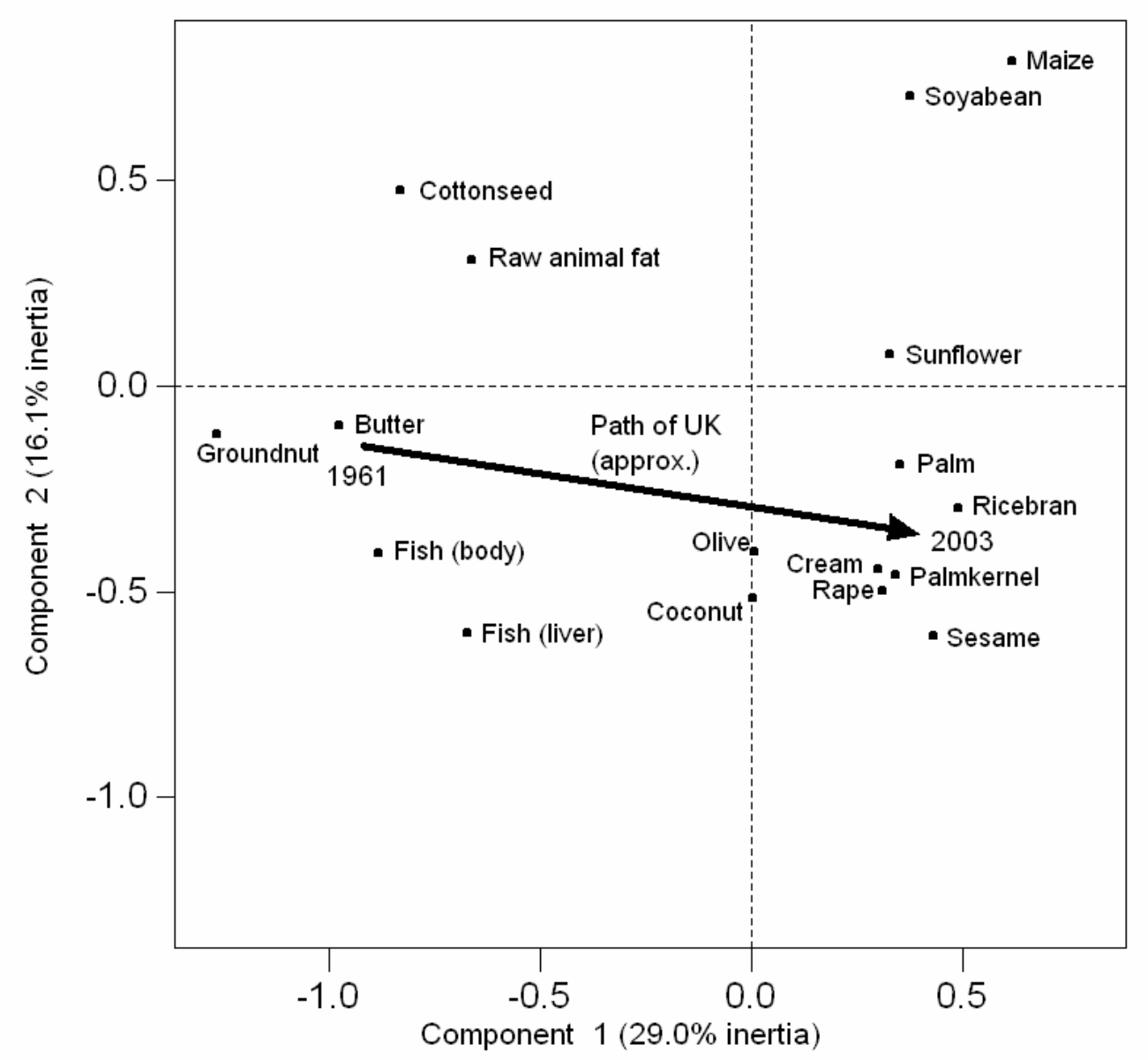

Figure 3a: Correspondence analysis - edible lipids plotted by their importation in different world regions in 1961 and 2003. 


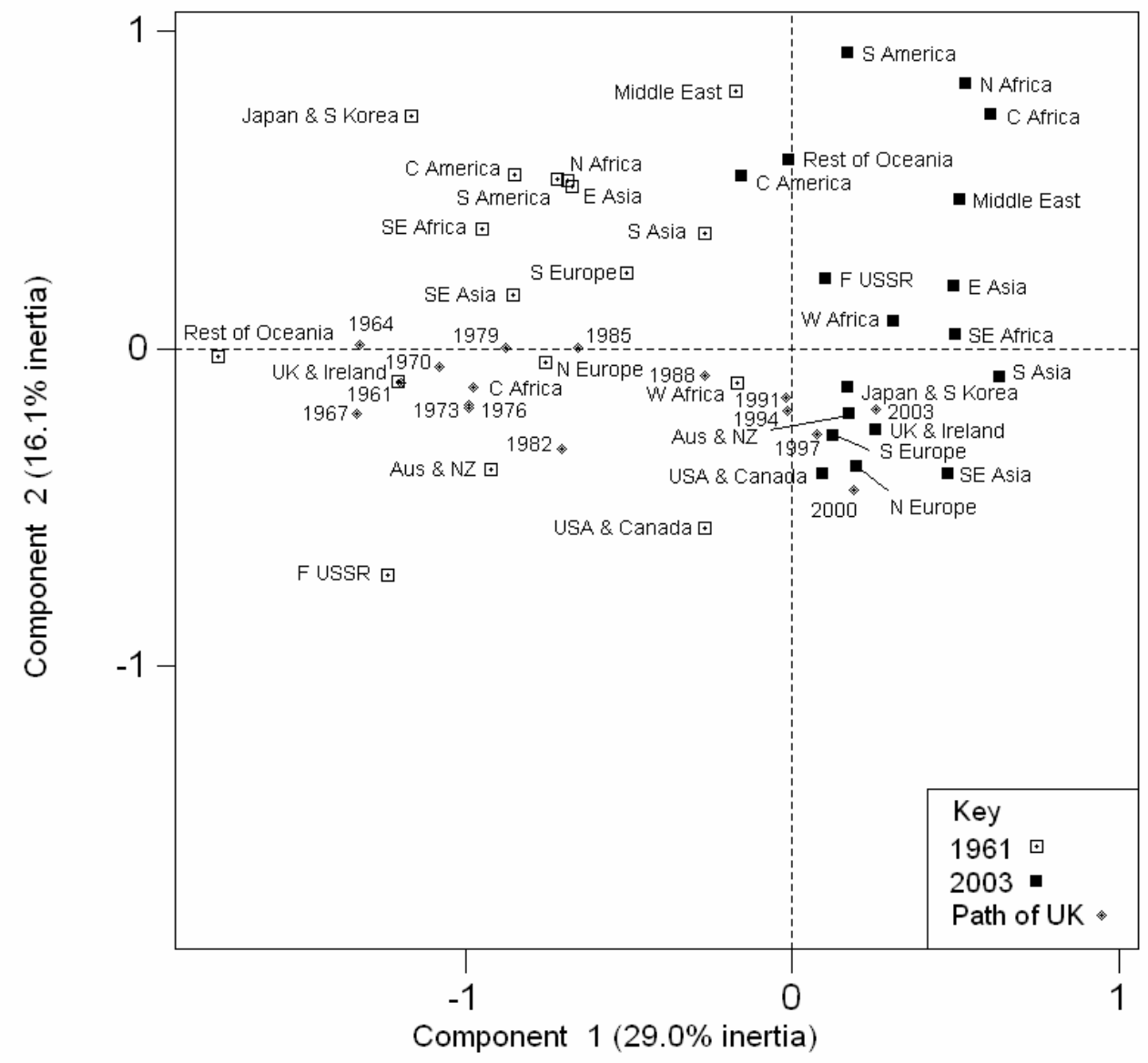

Figure 3b: Correspondence analysis - world regions plotted by the importation of different edible lipids in 1961 and 2003.

A prominent feature of figure $3 \mathrm{~b}$ is the split between patterns of lipid importation in 1961 (on the left of the plot) and 2003 (on the right), with the horizontal axis (component 1) accounting for change over time, moving from left to right. Although this pattern indicates a general shift in the importation of fats and oils since 1961, figure 3a shows that the nature of convergence appears to be towards an increased diversity in lipid intake, especially of vegetable oils (i.e. olive, coconut, palm, ricebran, palmkernel, rape, sesame and sunflower oil), in the lower-right quadrant. The main characteristics of this transition are less pronounced than for availability, including a general global shift away from animal fats (with the exception of cream) towards vegetable oils (on the right two quadrants). Whilst affluent regions (i.e. Europe, North America, Japan \& South Korea and Australia $\&$ New Zealand) closely converge on the cluster of vegetable oils in the lower-right quadrant, several poorer regions (e.g. Latin America, North and Central Africa and the Middle East) shifted towards the importation of maize and soyabean oil in the upper-right quadrant. Again, the gradual nature of the former pattern is illustrated by the supplementary points for the UK at three-year intervals, with the biggest changes apparently occurring in the mid-1980s. The main exceptions to this rich-poor split are less affluent regions in 2003 plotted on the edges of the wealthier cluster in the lower-right quadrant (especially parts of Asia and Africa), possibly indicating some localised trade in crops such as palm and sesame oil. 


\section{JOURNAL OF WORLD-SYSTEMS RESEARCH}

Table 3: World lipid imports, Kg/capita/year, 1961 (Source: FAOSTAT data, 2006).

\begin{tabular}{|c|c|c|c|c|c|c|c|c|c|c|c|c|c|c|c|c|c|}
\hline 후을 & 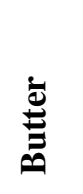 & 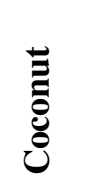 & 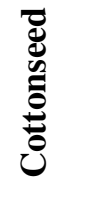 & 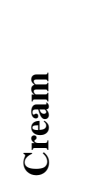 & 尝 & $\frac{\hat{\theta}}{0}$ & 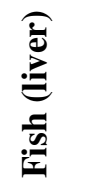 & 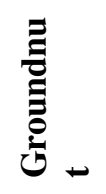 & 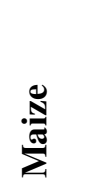 & 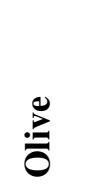 & Е & 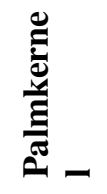 & 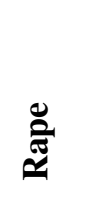 & : & 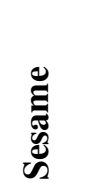 & 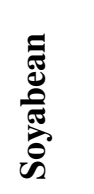 & 离 \\
\hline Aus \& NZ & 0.00 & 0.03 & 0.00 & 0.00 & 0.01 & 0.23 & 0.05 & 0.59 & 0.00 & 0.38 & 0.21 & 0.00 & 0.01 & 0.00 & 0.00 & 0.21 & 0.00 \\
\hline C Africa & 0.04 & 0.00 & 0.01 & 0.00 & 0.12 & 0.00 & 0.00 & 0.05 & 0.00 & 0.10 & 0.02 & 0.01 & 0.00 & 0.00 & 0.00 & 0.00 & 0.00 \\
\hline C America & 0.11 & 0.21 & 0.31 & 0.00 & 2.08 & 0.02 & 0.00 & 0.00 & 0.00 & 0.10 & 0.07 & 0.00 & 0.00 & 0.00 & 0.00 & 0.14 & 0.42 \\
\hline E Asia & 0.00 & 0.03 & 0.00 & 0.00 & 0.07 & 0.00 & 0.00 & 0.02 & 0.00 & 0.00 & 0.00 & 0.00 & 0.00 & 0.00 & 0.00 & 0.04 & 0.00 \\
\hline F USSR & 0.04 & 0.01 & 0.00 & 0.00 & 0.04 & 0.15 & 0.00 & 0.00 & 0.00 & 0.02 & 0.00 & 0.00 & 0.03 & 0.00 & 0.00 & 0.00 & 0.00 \\
\hline Japan \& S Korea & 0.00 & 0.00 & 0.04 & 0.00 & 2.15 & 0.00 & 0.00 & 0.00 & 0.00 & 0.00 & 0.12 & 0.00 & 0.00 & 0.00 & 0.00 & 0.00 & 0.00 \\
\hline Middle East & 0.16 & 0.04 & 0.21 & 0.00 & 0.32 & 0.01 & 0.00 & 0.00 & 0.00 & 0.03 & 0.17 & 0.00 & 0.00 & 0.00 & 0.00 & 0.63 & 0.26 \\
\hline N Africa & 0.24 & 0.07 & 0.32 & 0.00 & 0.97 & 0.01 & 0.00 & 0.32 & 0.00 & 0.07 & 0.14 & 0.01 & 0.13 & 0.00 & 0.00 & 0.57 & 0.32 \\
\hline N Europe & 0.30 & 0.46 & 0.59 & 0.00 & 2.39 & 2.17 & 0.07 & 0.28 & 0.01 & 0.08 & 1.40 & 0.10 & 0.08 & 0.00 & 0.00 & 0.53 & 0.77 \\
\hline Rest of Oceania & 0.40 & 0.00 & 0.00 & 0.00 & 0.38 & 0.00 & 0.00 & 0.47 & 0.00 & 0.00 & 0.00 & 0.00 & 0.07 & 0.00 & 0.00 & 0.00 & 0.00 \\
\hline S America & 0.05 & 0.08 & 0.03 & 0.00 & 0.61 & 0.01 & 0.00 & 0.04 & 0.00 & 0.07 & 0.05 & 0.01 & 0.00 & 0.00 & 0.00 & 0.19 & 0.02 \\
\hline S Asia & 0.00 & 0.02 & 0.03 & 0.00 & 0.08 & 0.00 & 0.00 & 0.00 & 0.00 & 0.00 & 0.06 & 0.00 & 0.02 & 0.00 & 0.00 & 0.04 & 0.00 \\
\hline SE Asia & 0.01 & 0.04 & 0.00 & 0.00 & 0.17 & 0.00 & 0.00 & 0.02 & 0.00 & 0.00 & 0.05 & 0.00 & 0.00 & 0.00 & 0.00 & 0.00 & 0.00 \\
\hline SE Africa & 0.04 & 0.16 & 0.14 & 0.00 & 0.71 & 0.01 & 0.00 & 0.02 & 0.00 & 0.02 & 0.08 & 0.02 & 0.00 & 0.00 & 0.00 & 0.03 & 0.00 \\
\hline S Europe & 0.05 & 0.14 & 0.01 & 0.00 & 1.25 & 0.22 & 0.01 & 0.63 & 0.00 & 0.71 & 0.57 & 0.06 & 0.01 & 0.00 & 0.00 & 1.02 & 0.04 \\
\hline UK \& Ireland & 7.83 & 0.74 & 0.14 & 0.00 & 5.87 & 2.98 & 0.04 & 0.67 & 0.00 & 0.05 & 3.19 & 0.02 & 0.00 & 0.00 & 0.00 & 0.42 & 0.06 \\
\hline USA and Canada & 0.00 & 0.48 & 0.09 & 0.00 & 0.19 & 0.22 & 0.03 & 0.02 & 0.05 & 0.14 & 0.23 & 0.19 & 0.01 & 0.00 & 0.00 & 0.05 & 0.00 \\
\hline W Africa & 0.02 & 0.01 & 0.00 & 0.00 & 0.04 & 0.00 & 0.00 & 0.02 & 0.00 & 0.01 & 0.12 & 0.00 & 0.00 & 0.00 & 0.00 & 0.02 & 0.00 \\
\hline
\end{tabular}


Figure 4, showing CA of lipid imports lumped into composite categories, clarifies many of the trends highlighted from figure 3 , in particular the global shift away from animal fat imports (in the left pair of quadrants) towards vegetable oils (on the right). Whilst the horizontal axis (component 1) reflects the passage of time, the vertical axis (component 2) seems to differentiate regions based on economic well-being, especially for 2003. Whereas clusters of poorer regions in 2003 correspond to soyabean oil (e.g. North and Central Africa in the upper-right quadrant), sunflower oil (e.g. West Africa, south-east Africa and South Asia to the right of the plot center), the bulk of richer countries converge towards olive oil, rape and other vegetable oils in the lower right quadrant. This is in stark contrast to the results of $\mathrm{CA}$ on overall availability per capita, which isolated olive oil as a predominantly southern European and Mediterranean staple. Indeed, the importation of olive oil (in addition to rape oil) seems to be a major factor distinguishing affluent regions from those less wealthy. The wider implications of the patterns highlighted in figures 3 and 4 are discussed below, alongside those trends already noted above in the analysis of lipid availability.

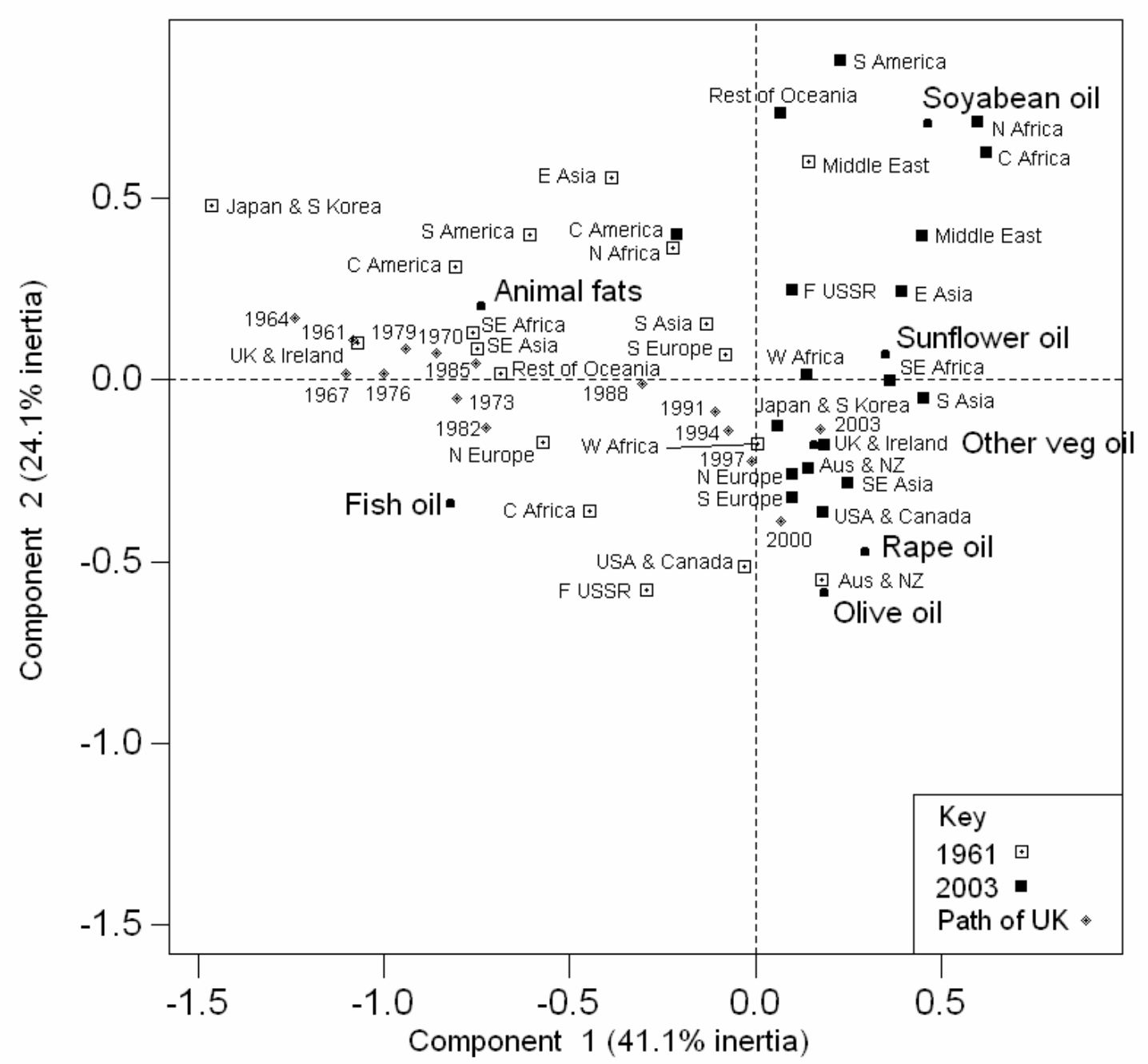

Figure 4: Correspondence analysis - the importation of simplified edible lipid categories by world region in 1961 and 2003. 


\section{JOURNAL OF WORLD-SYSTEMS RESEARCH}

Table 4: World lipid imports, Kg/capita/year, 2003 (Source: FAOSTAT data, 2006).

\begin{tabular}{|c|c|c|c|c|c|c|c|c|c|c|c|c|c|c|c|c|c|}
\hline 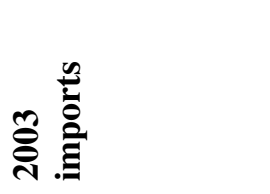 & $\underbrace{\grave{Z}}_{0}$ & હٍ & 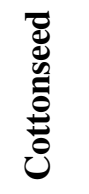 & 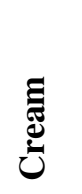 & 幽 & 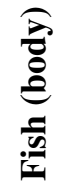 & $\underset{\substack{0 \\
:}}{:}$ & 竔 & 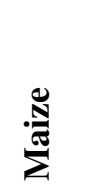 & 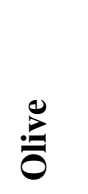 & $\stackrel{\Xi}{\tilde{\sigma}}$ & 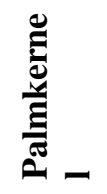 & 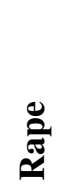 & 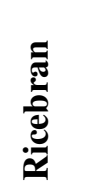 & $\begin{array}{l}\underset{\Xi}{E} \\
\underset{\mathscr{E}}{\mathscr{E}}\end{array}$ & 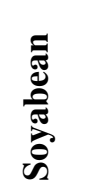 & 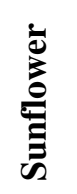 \\
\hline Aus \& NZ & 0.37 & 1.11 & 0.23 & 0.17 & 2.10 & 0.43 & 0.02 & 0.07 & 0.13 & 1.37 & 6.03 & 0.55 & 1.12 & 0.00 & 0.07 & 1.54 & 1.68 \\
\hline C Africa & 0.02 & 0.00 & 0.01 & 0.00 & 0.05 & 0.00 & 0.00 & 0.00 & 0.01 & 0.01 & 0.69 & 0.00 & 0.10 & 0.00 & 0.00 & 1.02 & 0.05 \\
\hline C America & 0.37 & 0.23 & 0.11 & 0.12 & 4.82 & 0.05 & 0.00 & 0.00 & 0.25 & 0.09 & 2.43 & 0.30 & 0.53 & 0.00 & 0.00 & 2.94 & 0.64 \\
\hline E Asia & 0.03 & 0.12 & 0.00 & 0.01 & 0.43 & 0.01 & 0.00 & 0.02 & 0.02 & 0.01 & 3.09 & 0.12 & 0.16 & 0.00 & 0.00 & 1.53 & 0.05 \\
\hline F USSR & 0.63 & 0.38 & 0.05 & 0.04 & 1.09 & 0.01 & 0.00 & 0.00 & 0.10 & 0.03 & 1.83 & 0.08 & 0.17 & 0.00 & 0.00 & 1.16 & 1.57 \\
\hline Japan \& S Korea & 0.08 & 0.60 & 0.09 & 0.01 & 1.20 & 0.55 & 0.01 & 0.00 & 0.05 & 0.22 & 4.06 & 0.35 & 0.20 & 0.13 & 0.01 & 1.18 & 0.14 \\
\hline Middle East & 0.43 & 0.11 & 0.10 & 0.04 & 0.84 & 0.01 & 0.00 & 0.00 & 0.85 & 0.07 & 6.16 & 0.43 & 0.16 & 0.00 & 0.01 & 4.75 & 1.51 \\
\hline N Africa & 0.68 & 0.05 & 0.00 & 0.01 & 0.19 & 0.00 & 0.00 & 0.00 & 0.97 & 0.17 & 1.59 & 0.03 & 0.40 & 0.00 & 0.00 & 4.82 & 2.58 \\
\hline N Europe & 1.95 & 3.74 & 0.01 & 1.19 & 3.75 & 1.86 & 0.03 & 0.31 & 0.26 & 0.48 & 15.69 & 2.47 & 4.73 & 0.00 & 0.02 & 3.20 & 3.72 \\
\hline Rest of Oceania & 0.60 & 0.00 & 0.00 & 0.29 & 0.35 & 0.01 & 0.00 & 0.13 & 0.04 & 0.08 & 0.31 & 0.05 & 0.05 & 0.00 & 0.00 & 1.51 & 0.43 \\
\hline S America & 0.03 & 0.01 & 0.00 & 0.01 & 0.96 & 0.19 & 0.00 & 0.00 & 0.06 & 0.08 & 0.44 & 0.11 & 0.03 & 0.00 & 0.00 & 2.23 & 0.49 \\
\hline S Asia & 0.01 & 0.08 & 0.00 & 0.00 & 0.11 & 0.00 & 0.00 & 0.00 & 0.00 & 0.00 & 4.48 & 0.14 & 0.01 & 0.03 & 0.01 & 1.04 & 0.08 \\
\hline SE Asia & 0.09 & 0.24 & 0.00 & 0.07 & 0.06 & 0.03 & 0.00 & 0.00 & 0.05 & 0.01 & 1.72 & 0.23 & 0.02 & 0.00 & 0.01 & 0.20 & 0.05 \\
\hline SE Africa & 0.03 & 0.05 & 0.06 & 0.01 & 0.37 & 0.01 & 0.00 & 0.01 & 0.05 & 0.03 & 3.48 & 0.15 & 0.04 & 0.00 & 0.00 & 0.98 & 0.31 \\
\hline S Europe & 0.95 & 0.90 & 0.05 & 0.92 & 2.29 & 0.42 & 0.01 & 0.47 & 0.43 & 3.19 & 6.25 & 0.53 & 1.27 & 0.00 & 0.01 & 1.21 & 3.32 \\
\hline UK \& Ireland & 1.93 & 1.65 & 0.01 & 0.27 & 2.17 & 0.91 & 0.08 & 0.14 & 0.07 & 0.90 & 12.93 & 1.27 & 2.38 & 0.00 & 0.05 & 2.51 & 5.74 \\
\hline USA and Canada & 0.19 & 1.14 & 0.15 & 0.03 & 0.84 & 0.18 & 0.01 & 0.03 & 0.14 & 0.74 & 0.78 & 0.71 & 1.35 & 0.00 & 0.04 & 0.84 & 0.15 \\
\hline W Africa & 0.03 & 0.01 & 0.02 & 0.00 & 0.62 & 0.01 & 0.00 & 0.01 & 0.01 & 0.01 & 2.31 & 0.03 & 0.05 & 0.00 & 0.00 & 0.58 & 0.01 \\
\hline
\end{tabular}




\section{DISCUSSION}

Analysis of the global availability and importation of fats and oils for human consumption in the last 50 years reveals many inherent contradictions in the globalization of food. At a general level, both imports and the broad availability of edible lipids displayed an overwhelming degree of convergence from 1961 to 2003, especially in terms of a global transition away from animal fats towards vegetable oils. However, whereas the net availability of fats and oils shifted from a situation characterised by regional diversity in 1961 to a picture of increased uniformity and dependence on one or two dominant crop varieties in 2003 (i.e. soyabean and rape oil), the global importation of lipids paradoxically tended towards significantly increased diversity, especially of imports into more affluent regions. This suggests two complementary processes at work - firstly the homogenization of cheap mass produced food as a larger proportion of the world's population becomes more integrated into a global economy, and secondly, a shift from regional food diversity to increased food choice in the supermarkets and delicatessens of wealthier regions (for those who have both the desire and means to consume internationally). To take one extreme national example, it is perhaps no coincidence that the mid-1980s, the period of highest growth in income inequality in the UK (Brewer, Goodman and Leicester 2006), also bears witness to the most rapid changes in fats and oils imports into the UK (kick-starting a trend that continued at a slower pace thereafter to define patterns of British edible lipid imports into the early 21st century; see figures 4 and 5). The net effect of globalization on the availability of fats and oils is to both homogenize consumption for the world's majority, whilst simultaneously increasing consumer choice and hybridity for the wealthier minority. In this context, although there are undeniably health benefits from consuming more vegetable oils as opposed to animal fats, the causes of this general transition are inherently more likely to have resulted from the relative cheapness of certain vegetable oils as opposed to middle class health concerns.

Another notable feature of the analysis conducted in this study was its ability to distinguish trends in economic well-being. For example, in terms of lipid availability, the poorest regions such as Central Africa, Western Africa and south-east Asia clustered for 1961 and 2003, being among the most resistant areas to globalizing trends (figure 2), whereas in terms of lipid imports, the most wealthy regions clustered, being able to bring in a diverse range of fats and oils (figure 4). Patterns such as these reflect the changes in global lipid production in the last century, with richer countries at the forefront of the production of newer varieties (especially soyabean and oilseed rape), and the rest of the world catching up (although no doubt by the time they have tastes will have changed again). The relative inability of the world's poorest regions to participate in this otherwise global phenomenon could be arguably cited as yet another indicator of the increasing gulf between the world's haves and have-nots. Compared to the general availability of lipids, the patterns of imports are much more influenced by demand (of the more affluent sections of society), perhaps driven by current western middle-class values such as healthy eating, a little ethical consumption and even the need to distance oneself from the harsh inequalities of the global economic system. We contend that this more likely provides yet another example of the inherent role of inequality in globalization, rather than representing any counter-movement to globalization process.

The trends in global lipid availability and consumption we show illustrate how homogenization can occur that may appear to some as if collusion amongst transnational corporations is at work (Kentor 2005). That is not to say that there is evidence of any collusion or conspiracy among such corporations, as actual collusion is not necessary to produce such a pattern of homogenization (Nollert 2005). Others might see the homogenization of lipid consumption evidence of globalization or some kind of imperialism. After all globalization is often "a cleansed term for imperialism" (Laxer 2005: 318). Are we seeing the imposition of a hegemonic American diet worldwide? As Henry Kissinger is reported to have said in 1999 "[W]hat is called globalization is really another name for the dominant role of the United States" (Laxer 2005: 328). Studying the world geography of oils and fats for evidence pointing one way or the other of US dominance has a certain irony, especially given our environmental current fears that "if the Chinese eat as many eggs and drive as many cars per capita as citizens of the United States do, the global biosphere will fry" (Chase-Dunn 2005: 188).

Allaying fears of hegemonic cuisine dominance apart, in addition to providing an indicator of broad trajectories in food availability and imports, this study isolated some more specific spatial and 
temporal trends of importance. Most striking was the distinctiveness of certain regions, such as the Mediterranean, which retained the unique association with olive oil with little relative change from 1961 to 2003. Although environmental determinists would see the Mediterranean as representing the logical optimum productive geographical area of the olive, it can be argued the impetus for the spread of the olive in the first place was political, to feed frontier armies and the urbanised core of the Roman Empire (Hopkins 1980; Woolf 1990). In a similar vein, it is apparent from the present study that more recent large geo-political formations have their own primary source of lipids (e.g. the EU oilseed rape, the former USSR - sunflower oil, and the USA - soyabean), and that remnants of older political entities can be hitherto read in this fashion (e.g. the British Empire - animal fats, and the Roman Empire - olive oil). Indeed, it is worth noting that the biggest increase in oilseed rape availability in the UK is in the period following entry into the European Common Market in 1973 (figure 5; Tanaka, Juska and Busch 1999). These patterns seem to represent the impact of overarching food policy, creating regimes of production and consumption which have become synonymous with regional food cultures.

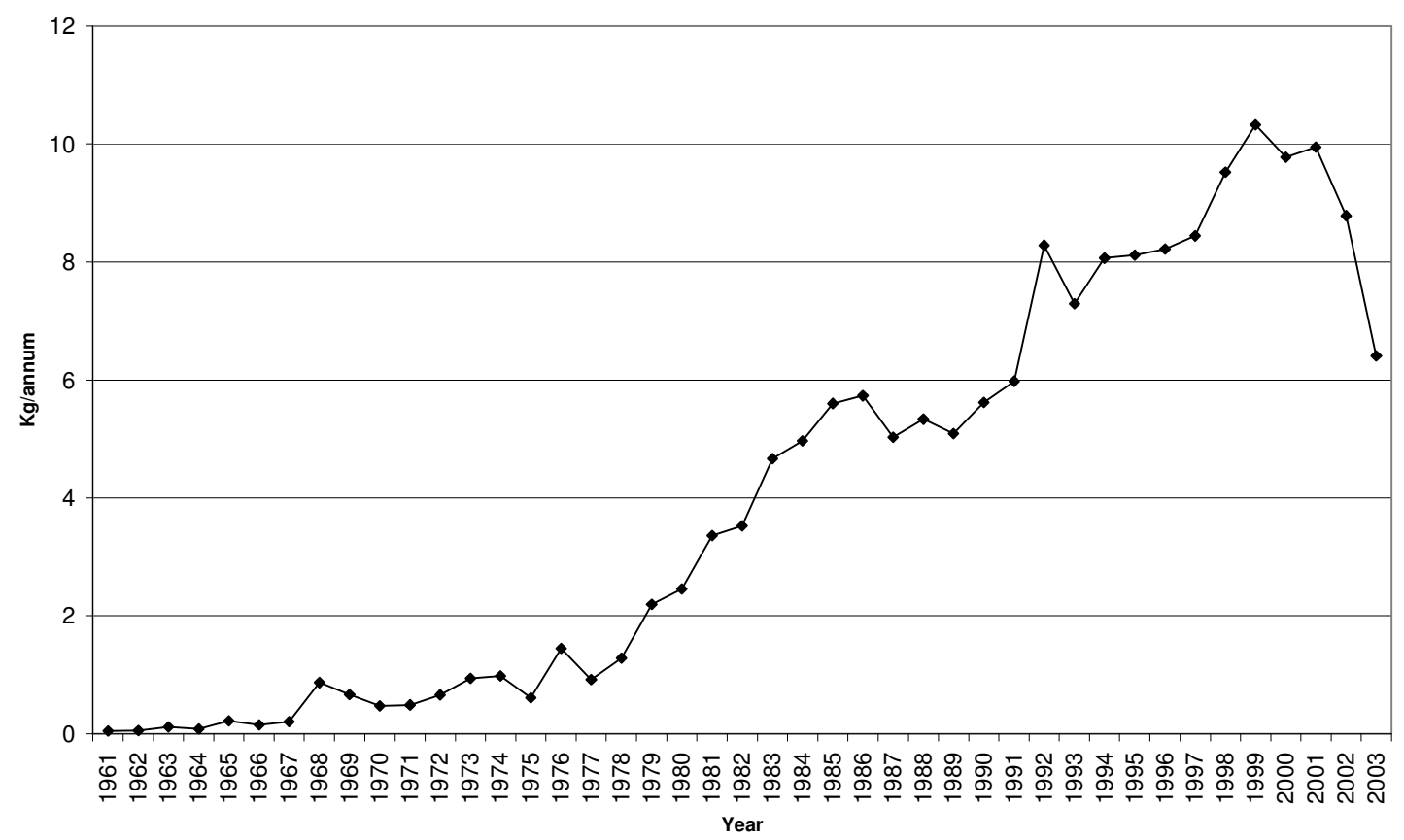

Figure 5: Rape oil availability in the UK, 1961-2003 (Source: FAOSTAT data, 2006).

\section{CONCLUSION}

This paper highlights the value of fats and oils in elucidating meaningful regional variations in food consumption, especially compared to other bulk food commodities (e.g. cereals). Our results appear to confirm the notion that global dietary shifts are filtered through relations of inequality (McMichael 2001), both in terms of class and regionality. As Bauman (1998: 2) states, "globalization divides as much as it unites; it divides as it unites - the causes of division being identical with those which promote the uniformity of the globe". If it is true that "food embodies history like no other substance" (McMichael 2001: 216), then lipids can be seen to oil the regional machinations of such change over both long (centuries) and short (decades) time periods. In spite of the relatively crude resolution (using bulk commodity availability and imports per capita in lieu of figures concerning actual consumption), it has been demonstrated that edible lipids are particularly sensitive indicators of globalization processes. However, the extent to which the general homogenization of global lipid availability witnessed here is actively moulding new habits or being passively incorporated into local cultures of consumption (Jackson 2004) remains uncertain. A number of central questions beyond the 
scope of our data remain unanswered, not least concerning the issue of consumer choice, which can more meaningfully addressed from household survey data, trends in the international trade in processed foods, and the changing relationship between lipids and the content of regional cuisines across the world. In particular, further distinctions need to be drawn between the conscious choice of fats and oils for cooking within the household, and the consumption of lipids that have been already incorporated into processed fare by the food industry.

\section{ACKNOWLEDGEMENTS}

This paper arose from the Leverhulme funded 'Changing Families, Changing Food' project, based at the University of Sheffield. Danny Dorling is supported by a research leave fellowship awarded by the British Academy.

\section{REFERENCES}

Bauman, Z. 1998. Globalization: The Human Consequences. Cambridge: Polity Press.

Bourdieu, P. 1984. Distinction: A Social Critique of the Judgement of Taste. London: Routledge.

Brewer, M., A. Goodman, and A. Leicester. 2006. Household Spending in Britain. What Can it Teach Us About Poverty? Bristol: Polity Press.

Brunner, E. 2006. "Oily Fish and Omega 3 Fat Supplements”. British Medical Journal 332: 739-740.

Brunner, E. J., M. G. Marmot, K. Nanchahal., M. J. Shipley, S. A. Stansfeld., M. Juneja,and K.G.M.M.Alberti. 1997. "Social Inequality in Coronary Risk: Central Obesity and the Metabolic Syndrome. Evidence from the Whitehall II Study". Diabetologia 40: 1341-1349.

Chase-Dunn, C. 2005. "Social Evolution and the Future of World Society". Journal of World-Systems Research 11(2): 171-194.

Chase-Dunn, C., Y. Kawano, and B. D. Brewer. 2000. "Trade Globalization Since 1795: Waves of Integration in the World-System". American Sociological Review 65: 77-95.

Cool, H.E.M., and M. J. Baxter. 2002. "Exploring Romano-British Finds Assemblages". Oxford Journal of Archaeology 21: 365-80.

Cordain, L., S. B. Eaton., A. Sebastian, N. Mann, S. Lindeberg, B. A. Watkins, J. H. O’Keefe, and J. Brand-Miller. 2005. "Origins and Evolution of the Western Diet: Health Implications for the 21st century". American Journal of Clinical Nutrition 81: 341-354.

Dyson, T. 1996. Population and food. Global Trends and Future Prospects. London: Routledge.

Erikson, E., and P. Bearman. 2006. "Malfeasance and the Foundations for Global Trade: The Structure of English Trade in the East Indies, 1601-1833". American Journal of Sociology 112(1): 195-230.

Food and Agriculture Organisation Statistics Data. 2006. Food Balance Sheets, Rome: FAO. Accessed March 2006.

Food and Agriculture Organisation. 1994. Fats and Oils in Human Nutrition. Rome: FAO Food and Nutrition Papers 57.

Food and Agriculture Organisation. 2001. Food Balance Sheets. A Handbook. Rome: FAO.

Frank, A.G and B.K Gills. 2000. "The Five Thousand Year World System in Theory and Praxis." Pp. 3-23 in World System History. The Social Science of Long-term Change, edited by R. A. Denemark, J. Friedman, B. K. Gills, and G. Modelski. London: Routledge.

Gidez, L.I. 1984. "The Lore of Lipids". Journal of Lipid Research 25: 1430-36.

Gil, J.M., A. Gracia, and L Perez y Perez. 1995. "Food Consumption and Economic Development in the European Union". European Review of Agricultural Economics 22: 385-399.

Greenacre, M.J. 1993. Correspondence Analysis in Practice. London: Academic Press.

Greenacre, M.J., and T. Hastie. 1987. "The Geometric Interpretation of Correspondence Analysis". Journal of the American Statistical Association 82: 437-447.

Grigg, D. 1993. "The European Diet: Regional Variations in Food Consumption in the 1980s". Geoforum 24: 277-289. 


\section{JOURNAL OF WORLD-SYSTEMS RESEARCH}

Grigg, D. 1999a. "The Fat of the Land: A Geography of Oil and Fat consumption". GeoJournal 48: 259-268.

Grigg, D. 1999b. "The Changing Geography of World Food Consumption in the Second Half of the Twentieth Century". Geographical Journal 165: 1-11.

Grigg, D. 2001. "Olive Oil, the Mediterranean and the World". GeoJournal 53: 163-172.

Gunstone, F.D. 1989. "Oils and Fats - Past, Present and Future". Pp 1-16 in Fats for the Future, edited by R.C. Cambie. Chichester: Ellis Horwood Ltd.

Herrmann, R., and C. Röder. 1995. "Does Food Consumption Converge Internationally? Measurement, Empirical Tests and Determinants". European Review of Agricultural Economics 22: 400-414.

Hoffman, D.L., and G. R. Franke. 1986. "Correspondence Analysis: Graphical Representation of Categorical Data in Marketing Research". Journal of Marketing Research 23: 213-227.

Hopkins, K. 1980. "Taxes and Trade in the Roman Empire 200 B.C. - A.D. 400." Journal of Roman Studies 70:101-125.

Horden, P., and N. Purcell. 2000. The Corrupting Sea. London: Blackwell.

Jackson, P. 2004. "Local Consumption Cultures in a Globalizing World". Transactions of the Institute of British Geographers 29: 165-178.

Kennedy, G., G. Nantel, and P. Shetty. 2004. "Globalization of Food Systems in Developing Countries: A Synthesis of Country Case Studies". Pp 1-25 in Globalization of Food Systems in Developing Countries: Impact on Food Security and Nutrition. Rome: Food and Agriculture Organization of the United Nations Paper 83.

Kentor, J. 2005. "The Growth of Transnational Corporate Networks: 1962-1998". Journal of WorldSystems Research 11(2): 263-288.

Lang, T. 1999. "The Complexities of Globalization: The UK as a Case Study of Tensions Within the Food System and the Challenge to Food Policy". Agriculture and Human Values 16: 169-185.

Laxer, G. 2005. "Popular National Sovereignty and the U.S. Empire". Journal of World-Systems Research 11(2): 317-354.

Lieberman, L.S. 2003. "Dietary, Evolutionary, and Modernizing Influences on the Prevalence of Type 2 Diabetes". Annual Review of Nutrition 23: 345-377.

Marr, J.W. 1985. “Interpreting Dietary Recommendations”. Pp 200-207 in The Role of Fats in Human Nutrition, edited by: F.B. Padley and J. Podmore. London: Ellis Horwood.

Martinelli, A. 2005. "From World System to World Society?" Journal of World-Systems Research 11(2): 241-262.

Mattingly, D. 1988. "Oil for Export? A Comparison of Libyan, Spanish and Tunisian Olive Oil Production in the Roman empire". Journal of Roman Archaeology 1: 33-56.

McMichael, P. 2001. "The Impact of Globalisation, Free Trade and Technology on Food and Nutrition in the New Millennium". Proceedings of the Nutrition Society 60: 215-220.

McNutt, K.W., and D. R. McNutt. 1978. Nutrition and Food Choices. Chicago: Science Research Associates.

Millstone, E., and T. Lang. 2003. The Atlas of Food. Brighton: Earthscan.

Nayyar, D. 2006. "Globalisation, History and Development: A Tale of Two Centuries". Cambridge Journal of Economics 30: 137-159.

Nollert, M. 2005. "Transnational Corporate Ties: A Synopsis of Theories and Empirical Findings". Journal of World-Systems Research 11(2): 289-316.

O’Rourke, K.H., and Williamson, J.G. 2002. "When Did Globalisation Begin?". European Review of Economic History 6: 23-50.

Pitts, M. 2005. "Pots and Pits: Drinking and Deposition in Late Iron Age South-East Britain". Oxford Journal of Archaeology 24: 143-61.

Popkin, B.M. 2003. "The Nutrition Transition in the Developing World". Development Policy Review 21: 581-597.

Power, C., and C. Moynihan. 1988. "Social Class and Changes in Weight-for-Height between Childhood and Early Adulthood". International Journal of Obesity 12: 445-453.

Shennan, S. 1997. Quantifying Archaeology. Edinburgh: Edinburgh University Press.

Tanaka, K., A. Juska, and L. Busch. 1999. "Globalization of Agricultural Production and Research: The Case of the Rapeseed Subsector". Sociologia Ruralis 39: 54-77. 
Toussaint-Samat, M. 1992. A History of Food. Oxford: Blackwell.

Triall, B. 1997. "Globalisation in the Food Industries?". European Review of Agricultural Economics 24: 390-410.

Trichopoulou, A., A. Naska, and T. Costacou. 2002. "Disparities in Food Habits Across Europe". Proceedings of the Nutrition Society 61: 553-558.

Vergroesen, A.J., and J.J. Gottenbos. 1975. "The Role of Fats in Human Nutrition: An Introduction. Pp 1-41 in The Role of Fats in Human Nutrition, edited by A.J. Vergroesen. London: Academic Press.

Wallerstein, I. 19745. The Modern World System I. Capitalist Agriculture and the Origins of the European World-Economy in the Sixteenth Century. New York: Academic Press.

Watson, A. 2006. "It's Oil You Need". Metro, March 23, pp. 17.

Woolf, G. 1990. "World Systems Analysis and the Roman Empire." Journal of Roman Archaeology 3:44-58. 